\title{
Investigação e análise dos processos de gestão da informação em uma empresa do setor de call centers
}

\section{Eduardo Augusto Andrade}

\author{
Mestre em Administração de Empresas \\ (FEAD).Professor Centro Universitario UNA e \\ IBMEC
}

Rivadávia Correia Drummond Alvarenga Neto

Doutor em Ciência da Informação- UFMG Professor Fundação Dom Cabral

Este trabalho investiga e analisa as práticas e os processos de gestão estratégica informacional implementados em um call center, embasando-se em quatro categorias analíticas: determinação de exigências informacionais, obtenção, disseminação e uso de informações. Múltiplas fontes de evidências foram utilizadas, como quatorze entrevistas semi-estruturadas, pesquisa documental e observação direta. Os resultados apontaram para a inexistência de uma estrutura legítima de gestão estratégica da informação, e evidenciaram a distância entre o discurso e a prática vigente.

Palavras chave: Gestão estratégica da informação; Processos de gerenciamento da informação; Call center.

\section{Investigation and analysis of information management processes in a call center firm}

This article investigates and analyzes the practices and processes of strategic information management implemented in a call center. It was based on four categories of analysis: determination of information demands, acquisition, distribution and information use. Multiple sources of evidences were used, such as fourteen semi-structured interviews, document search and direct observation. of the research project quality, the following criteria were used: construct validity, external validity and reliability.isto não estava no resumo em português. The 
results suggested the lack of a legitimate structure of strategic management of information, showing the gap between discourse and real practice ..

Keywords: Strategic information management; Information management processes; Call center.

Recebido em 06.03.2009 Aceito em24.07.2009

\section{Introdução}

A emergência de um paradigma técno-econômico baseado em inovação, informação e conhecimento, bem como a crescente consolidação de tecnologias como a microeletrônica, a tecnologia de informação e as redes de computadores, trazem à tona questões complexas e multifacetadas para as organizações contemporâneas. Especial atenção tem sido devotada à questão da gestão da informação no ambiente organizacional, visto que a explosão da produção informacional implica que o desafio organizacional contemporâneo traduz-se em aprender a navegar em um oceano de informações, prospectando e coletando aquelas que são relevantes para a sobrevivência/prosperidade organizacional e para a compreensão de um ambiente de negócios cada vez mais dinâmico e mutável.

Sobreviver neste contexto envolve mais do que somente ter acesso à informação. Atualmente, as empresas têm que ajustar seus modi operandi não apenas ao esforço de busca da informação, mas principalmente ao uso que se faz dela através de seu gerenciamento. A partir dessa prerrogativa, as empresas têm que agir em tempo real quanto a seus problemas, desafios e decisões, usando substancialmente a informação de forma contundente e estratégica nas tomadas de decisões.

Nesse contexto, surge uma nova gestão, baseada em uma arquitetura informacional que deve resolver questões como o atendimento às necessidades de informação de todos os níveis da organização, além de integrar volumes crescentes de informações endógenas e exógenas ao ambiente organizacional. É inegável a necessidade de mecanismos de criação e implantação de processos e sistemas que armazenem, gerenciem e disseminem a informação.

Com a emergência de tantos assuntos em voga relacionados à era da informação, alguns desses chamam demasiadamente a atenção pela representatividade a que se propõem enquanto uma espécie de elemento de segurança para os desafios destes tempos. A gestão estratégica da informação (GEI) guarda uma condição envolta por uma expectativa salvatoriana sobre os problemas gerados pela explosão da produção informacional.

Os call centers, fruto da sociedade da informação, trabalham com uma ampla base de dados e um grande fluxo de informações para gerenciar seus processos internos. Estes últimos, além de atenderem às 
demandas de seus clientes contratantes, tendem a ser um caminho cada vez mais imbuído de práticas de gestão informacional.

Dada a importância do contexto e as dificuldades enfrentadas por estas organizações em seus ambientes informacionais, este trabalho fruto de uma dissertação de mestrado - dedica-se a uma análise sobre os desafios da gestão estratégica da informação, bem como à importância do uso da mesma para a administração da informação no ambiente de uma empresa representante do setor de call centers. Nessa direção, pretendese verificar qual o tratamento dispensado ao conceito de GEI, tomando por base um estudo a partir do modelo proposto por Davenport (1998), que trata dos processos de gerenciamento da informação.

Os esforços aplicados ao projeto em questão evidenciam-se na tentativa de responder à seguinte pergunta representada no problema de pesquisa: Quais são os processos e práticas de gestão estratégica da informação em uma empresa do setor de call center? Assim sendo, o objetivo deste trabalho é investigar e analisar as práticas e os processos vigentes de gestão estratégica da informação em uma empresa de call center.

A relevância deste problema se legitima na incapacidade das organizações e dos profissionais, especialmente dos call centers aqui considerados, de gerenciar suas informações estrategicamente com vistas à melhoria do processo decisório e à maximização de resultados. Os resultados deste estudo serão apresentados neste artigo.

\section{Referencial teórico}

\subsection{A era da informação e a explosão da produção informacional: os desafios da gestão estratégica da informação nas organizações}

O advento da era da informação trouxe consigo a grande produção e disponibilização de informações, ocasionando um desafio nos processos de identificação, acesso e utilização da informação (CHOO, 2003; LASTRES; FERRAZ, 1999; VON KROGH; ICHIJO; NONAKA, 2001). Estudos como os de Lyman e Varian (2003) ilustram o quão significativo é o volume de informações produzido, armazenado e processado mundialmente.

A sobrecarga de informações mostra-se como um grande problema para o homem deste século. Esse crescimento exacerbado é primeiramente um fenômeno orgânico sem diretriz ou estrutura aparente. Sua manifestação se dá através do excesso de informação que ultrapassa a capacidade do indivíduo de processá-la (LAZARTE, 2000).

Dessa forma, muitos têm sido os esforços para gerir a atividade informacional nas organizações. Bergeron (1996) sugere que há um reconhecimento crescente de que a informação, como qualquer outro recurso organizacional - financeiro, material e humano -, é um recurso que precisa ser gerenciado para ajudar as organizações a melhorarem sua produtividade, competitividade e performance geral. Devido à importância 
crescente do processo decisório, da inovação, do gerenciamento de processos e da aquisição e distribuição da informação na sociedade pósindustrial, a GEI surge como uma estratégia aperfeiçoada para o gerenciamento eficaz da informação, e como uma resposta aos problemas informacionais das organizações - obter a informação correta, na hora certa, na forma/meio correto e endereçá-la à pessoa certa. Essas informações podem concernir às atividades organizacionais - presentes e/ou passadas - ou a fatores ambientais; e podem ser gravadas em qualquer tipo de mídia, dentro ou fora da organização. A qualidade das decisões tomadas em uma organização pode ser afetada pela disponibilidade - para os tomadores de decisões - de informações, que sejam temporais, relevantes e qualitativamente suficientes para a resolução do(s) problema(s) proposto(s). Dessa maneira, as organizações devem estabelecer mecanismos necessários para a maximização da disponibilidade desse tipo de informação.

Uma visão holística do ambiente informacional em organizações é sugerida por uma miríade de autores e publicações da área. Tal discussão é objeto da próxima seção.

\subsection{Ecologia da informação e ambientes de informação em organizações: gestão da informação como processo organizacional}

Davenport (1998), no intuito de compreender as organizações em uma perspectiva integrativa sob o ponto de vista do uso da informação, propõe um modelo por ele denominado "ecologia da informação". Nessa perspectiva, são abordados elementos que compõem o universo informacional de uma organização, levando-se em consideração variáveis internas e externas interdependentes. Tal perspectiva é também corroborada por autores como Bergeron (1996), Choo (2003) e McGee e Prusak (1994), dentre outros.

A ecologia informacional de uma empresa é afetada por fatores externos, muitos dos quais as empresas não podem controlar de maneira direta. De acordo com Davenport (1998), o ambiente externo é composto por mercados de negócios, mercados tecnológicos e mercados de informação. Dentro do ambiente organizacional encontram-se as variáveis tecnologia, negócios e distribuição física.

O ponto nuclear do modelo ecológico é o ambiente informacional, onde se encontram seis componentes críticos: (1) política de informação, que se refere às questões voltadas ao poder propiciado pela informação; (2) cultura e o comportamento, que retratam a conduta da empresa no que diz respeito ao compartilhamento, obtenção de conhecimento e capacidade de iniciativa; (3) equipe multidisciplinar especializada em informação, entendida como o melhor meio para identificar, categorizar, filtrar, interpretar e integrar a informação; (4) estratégia da informação, vinculada à explicitação da intenção informacional e à estratégia da organização; (5) arquitetura informacional, que é um guia de estruturação 
e localização da informação; (6) processo de administração informacional ou processo de gerenciamento da informação, a base na qual se fundamenta este trabalho, que é composto por quatro etapas distintas determinação de exigências, obtenção, disseminação e uso de informações.

O processo de gerenciamento da informação pode ser conceituado como "um conjunto estruturado de atividades que incluem o modo como as empresas obtêm, distribuem e usam a informação e o conhecimento" (DAVENPORT, 1998, p.173). Sua proposta é apresentada pelos seguintes processos (McGEE; PRUSAK, 1994; BEAL, 2004):

1. identificação de necessidades informacionais: processo difícil, ambíguo e complexo, uma vez que deve ser levada em consideração a percepção sobre o ambiente informacional por parte dos funcionários e gerentes. As informações não estruturadas (notícias, idéias, rumores, exemplos de melhores práticas, dentre outras) enriquecem os dados concretos, tornando-os mais valiosos, além de adequá-los ao contexto;

2. obtenção de informações: deve ser entendida como uma atividade contínua; portanto, o processo somente é eficiente se considerado de maneira ininterrupta. Para isso, envolve as seguintes atividades: exploração do ambiente informacional, classificação das informações em uma estrutura pertinente, e, por fim, formatação e estruturação das informações;

3. distribuição de informações: está ligada à maneira como a informação é formatada e disseminada. Os melhores sistemas de distribuição acontecem de maneira híbrida e reúnem pessoas, computadores e documentos. Davenport (1998) cita os fatores que alteram a distribuição da informação segundo a perspectiva ecológica, como, por exemplo, uma arquitetura informacional eficiente - que conduz os usuários à informação de que precisam -, certos tipos de estruturas políticas - que tornam mais viável a distribuição entre as funções e as unidades - e o investimento tecnológico das empresas - que afeta diretamente a distribuição;

4. utilização de informações: a informação deve ser discutida no contexto de suas aplicabilidades, seus usos e resultados.

Cumpridos os objetivos relacionados ao referencial teórico, prosseguir-se-á, na próxima seção, com as discussões metodológicas ora propostas para este estudo.

\subsection{Call centers: a evolução da telefonia e da tecnologia no universo informacional}

"O advento do telefone de Alexander Graham Bell por volta de 1860 ajudou a acelerar a grande revolução da tecnologia, que transformou nosso mundo na sociedade de comunicação de massa de hoje" 
(McHATTON, 1990, p. 01). Graças a esta evolução, o mundo conheceu novas formas de comunicação que influenciaram o mercado e que implicaram uma corrida pelo melhor uso do telefone e da informação como atividade comercial. Independentemente das várias nomenclaturas, o call center refere-se a um local onde se prioriza e se estabelece o relacionamento com os clientes (MADRUGA, 2006).

O surgimento dos call centers confunde-se com o surgimento do telemarketing, atividade-fim dos mesmos. Villela et al. (2005) afirmam que os call centers não são um fenômeno novo, apenas o termo é relativamente recente, pois as antigas centrais de atendimento foram precursoras dos modernos call center. Segundo McHatton (1990), na década de 1980 "nasce" o termo telemarketing no Brasil junto com a chegada de multinacionais americanas. O uso do telefone ganhou impulso no Brasil na década de 90 com a promulgação do Código de Defesa do Consumidor (MADRUGA, 2006). Em conseqüência, as empresas criaram seus Serviços de Atendimento ao Consumidor (SACs), em resposta às novas diretrizes. Barbosa, Ferraz e Ávila (2004) somam a este fator a privatização do setor, o surgimento de empresas voltadas à telefonia móvel, além da Lei Geral de Telecomunicações e da demarcação inicial do arcabouço da Agência Nacional de Telecomunicações (ANATEL) em 1996.

No que tange à fusão da informática com o sistema de telefonia, novas possibilidades surgiram com a criação dos bancos de dados. Assim, call centers modernos tornaram-se ambientes cujo funcionamento é baseado em tecnologias das áreas de informação, computação e telecomunicações. O progresso tecnológico levou a um entrelaçamento cada vez maior dessas três áreas e, em particular, propiciou o desenvolvimento e a consolidação dos call centers (CALDAS; AZEVEDO, 2003).

Cassiolato e Lastres (1999) reforçam, nesse sentido, que a convergência entre telecomunicações e computação, principalmente através da tendência à digitalização, permite, do ponto de vista tecnológico, a ampliação das atividades dos call centers. Devido ao seu ambiente de funcionamento, são locais que se caracterizam pela mudança tecnológica constante e por um fluxo de informações intenso.

Cumpridos os objetivos relacionados ao referencial teórico, prosseguir-se-á, na próxima seção, com as discussões metodológicas ora propostas para este estudo.

\section{Metodologia}

A construção desta metodologia fundamentou-se no cuidado dedicado às escolhas de métodos que solidificassem os resultados e conseguissem extrair de forma fidedigna os resultados esperados.

O presente trabalho adotou procedimento metodológico conceituado como estudo de caso único com unidades de análise holísticas (YIN, 
2005). Foram utilizadas generalizações analíticas, que, ainda de acordo com Yin (2005), são próprias para estudos de caso nos quais se busca generalizar a compilação de resultados específicos da pesquisa dentro de um modelo teórico. Neste caso, utilizou-se o modelo de Davenport (1998), que trata de processos de gerenciamento de informações, conforme se segue: (i) determinação de exigências informacionais, (ii) obtenção de informações, (iii) distribuição de informações, e (iv) uso de informações.

Cada um desses processos foi tratado como uma categoria de análise, que remete diretamente a um objetivo específico. Segundo Alvarenga Neto, Barbosa e Cendón (2006, p. 79), "a intenção ao se estabelecer categorias é a de agrupar elementos, idéias e expressões em torno de conceitos capazes de sintetizar a análise meticulosa dos estudos de caso selecionados". A partir desta estratificação, foram criadas unidades de análise para melhor desenvolver a análise dos dados coletados em campo. As informações colhidas na análise de dados foram norteadas de forma a contemplar o objetivo geral e, consequentemente, atender à problemática de estudo.

Quanto ao julgamento da qualidade do projeto de pesquisa, optouse pelos seguintes critérios sugeridos por Yin (2005): validade do construto (múltiplas fontes de evidência para a mesma variável), validade externa (lógica de replicações, teóricas e literais) e confiabilidade (o estudo pode ser repetido obtendo-se resultados semelhantes).

Com base no arcabouço teórico, buscou-se o levantamento de evidências, em cada unidade de análise, que comprovassem a existência ou inexistência de processos de gerenciamento informacional. Para tanto, optou-se pela utilização de múltiplas fontes de evidências, através da fundamentação lógica de triangulação que, segundo Yin (2005), revigora o constructo e solidifica os resultados. Nesse sentido, foram utilizados os seguintes instrumentos de coleta de dados: (i) entrevistas semiestruturadas, com perguntas previamente formuladas, que servem para corroborar o que o investigador pensa a respeito de determinada situação (TRIVIÑOS, 1987; YIN, 2005); (ii) pesquisa documental (documentos físicos e arquivos eletrônicos); e (iii) observação direta. Tais instrumentos de coleta foram representados na forma de um protocolo de estudo de caso que, por sua vez, foi construído a partir de cada categoria analítica. O protocolo de estudo de caso, segundo Yin (2005), assegura a condução da investigação de forma fidedigna, além de aumentar a confiabilidade da pesquisa.

Através da amostra não probabilística por critério de acesso (MALHOTRA et al., 2005), entrevistaram-se representantes dos níveis estratégico, tático e operacional. Com vistas a um maior aprofundamento e compreensão dos fenômenos observados, optou-se por uma avaliação crítica e comparativa entre as respostas intra e inter-hierárquicas. Para a análise de dados coletados em campo, escolheu-se o modelo proposto por Miles e Huberman (1984), que propõe a análise dividida em três etapas, a saber: (a) redução de dados, (b) display ou exposição de dados, e (c) 
verificação/conclusões com base em inferências, a partir de evidências ou premissas.

\subsection{A pesquisa de campo}

A organização, objeto desse estudo, foi escolhida por critério de conveniência, em função da facilidade de acesso aos dados e contatos pessoais. A AFTAC é a representante no Brasil de uma joint venture européia especializada em call center, gestão de relacionamento e outsourcing de tecnologia da informação. O grupo é composto por 20 companhias, distribuídas em cinco países, conta com mais de 20 mil funcionários e seu faturamento em 2008 foi de 630 milhões de euros. A empresa almeja em cinco anos se posicionar entre as cinco maiores do Brasil em seu segmento e, para atingir esses objetivos, contou, somente em 2008, com um contingente de investimentos de $\mathrm{R} \$ 30$ milhões. Em 2007 conquistou - com seis meses desde o início das atividades - a certificação dos requisitos da Norma NBR ISO 9001:2000, que trata de Sistema de Gestão da Qualidade.

Ao total foram realizadas quatorze entrevistas, sendo que, destas, quatro entrevistas extras foram efetuadas de maneira complementar ao planejamento metodológico (QUADRO 1). Estas últimas ajudaram a esclarecer fenômenos pontuais, além de contribuírem para a elucidação de dúvidas decorrentes de entrevistas anteriores. Todas as entrevistas foram gravadas com o consentimento dos funcionários e o tempo médio de duração de cada entrevista foi de aproximadamente 1 hora e 40 minutos. Ao todo, foram registradas 23 horas e 20 minutos de gravação, gerando um total de 917 páginas de transcrições. Este material foi adicionado aos registros feitos em um caderno de anotações com o roteiro semiestruturado, follow-ups e particularidades das questões.

QUADRO 1- Entrevistas semi-estruturadas

\begin{tabular}{c|c|c|c}
\hline \multicolumn{4}{c}{ Primeira fonte de evidências: entrevistas semi-estruturadas } \\
\hline \hline & $\begin{array}{c}\text { Número de entrevistas } \\
\text { dentro do protocolo de } \\
\text { estudo de caso }\end{array}$ & $\begin{array}{c}\text { Número de entrevistas } \\
\text { complementares }\end{array}$ & Total \\
\hline Estratégico & 3 & 0 & 3 \\
\hline Tático & 3 & 3 & 6 \\
\hline Operacional & 4 & 1 & 5 \\
\hline Total & 10 & 4 & 14 \\
\hline
\end{tabular}

Fonte: Dados da pesquisa.

Através da segunda fonte de evidências - pesquisa documental foram analisados arquivos físicos e eletrônicos dos mais variados tipos, com um total de 696 páginas em 55 documentos (QUADRO 2): 
QUADRO 2- Pesquisa documental

\begin{tabular}{|c|c|c|c|}
\hline \multicolumn{4}{|c|}{ Segunda fonte de evidências: análise documental } \\
\hline \multirow{7}{*}{$\begin{array}{c}\text { Documentos } \\
\text { Físicos }\end{array}$} & & NÚMERO DE & NÚMERO DE \\
\hline & TIPO & DOCUMENTOS & PAGINAS \\
\hline & Jornal interno & 4 & 24 \\
\hline & Revista & & \\
\hline & especializada & 2 & 84 \\
\hline & Fotos & 10 & 10 \\
\hline & Folder & 2 & 6 \\
\hline \multirow{5}{*}{$\begin{array}{l}\text { Arquivos } \\
\text { eletrônicos }\end{array}$} & Word & 17 & 110 \\
\hline & PDF & 6 & 366 \\
\hline & Excel & 5 & 12 \\
\hline & Power Point & 5 & 36 \\
\hline & HTML & 4 & 48 \\
\hline Total & & 55 & 696 \\
\hline
\end{tabular}

Fonte: Dados da pesquisa.

Com um volume final de 1613 páginas de material pesquisado, fezse uso, como previsto, do modelo proposto por Miles e Huberman (1984) para a análise de dados coletados em campo. Foram necessários três ciclos de redução de dados para a inclusão do material coletado no corpo da dissertação, conforme demonstrado no QUADRO 3. Este processo usou como diretriz as matrizes construídas a partir das categorias de análise para a confecção dos displays ou a exibição de dados.

QUADRO 3- Ciclos de redução de dados

\begin{tabular}{c|cc}
\hline Processos de redução & De & Para \\
\hline \hline $1^{\circ}$ processo de redução & 1613 & 328 \\
\hline $2^{\circ}$ processo de redução & 328 & 40 \\
\hline $3^{\circ}$ processo de redução & 40 & Corpo da dissertação \\
\hline
\end{tabular}

Fonte: Dados da pesquisa.

Por fim, o nome AFTAC Call Center substitui o verdadeiro nome da empresa pesquisada por motivos de interesse da própria organização e dos acertos de confidencialidade. Da mesma forma, todos os nomes dos entrevistados, bem como seus cargos, foram omitidos, sendo os mesmos identificados apenas pelas letras que antecedem seu nível hierárquico e um número de identificação como: E1 (Estratégico), T3 (Tático), O2 (Operacional) e assim por diante. 


\section{Resultados}

\subsection{Categoria de análise 1: processo de determinação de exigências informacionais}

A informalidade do processo de diagnóstico de identificação de necessidades informacionais foi percebida em todos os níveis da organização, conforme o depoimento:

(...) quem mais procura saber de alguma coisa é o supervisor, (...) ele pergunta se a gente tá (sic) precisando de alguma coisa, mas é assim dessa forma (Entrevistado 01).

A busca por informações técnicas, que os colaboradores precisam para realizar seu trabalho, apontou principalmente para indicadores de produtividade da operação. As questões referentes aos hiatos ou gaps informacionais informações que os entrevistados gostariam de receber e não recebem levantaram as seguintes respostas: tratamento estratégico das informações do mailing, treinamentos, informações financeiras estratégicas, informações sobre a concorrência, conversões de vendas, necessidade de mecanismos de medição de eficácia e eficiência do staff, informações consistentes e atualizadas sobre promoções internas e processos seletivos, dentre outras. Contudo, três assuntos levantados merecem destaque, pela intensidade com que foram tratados e pela freqüência com que surgiram no decorrer das entrevistas: (a) treinamento, (b) informações sobre concorrência e (c) conversão de vendas. Dessa forma, confrontaram-se as avaliações dos entrevistados com a documentação pesquisada, o que mostrou um claro descompasso entre o discurso e a prática organizacional, evidenciando as causas dos gaps informacionais. Eis um depoimento que comprova tais assertivas:

(...) uma coisa que a gente não tem acesso é sobre a concorrência. (...) A gente tem a intranet. Só que a internet é uma coisa muito superficial, a gente não tem acesso realmente ao que é a concorrência (Entrevistado 03).

A conversão de vendas aqui tratada pode ser conceituada, segundo os entrevistados, como o percentual de efetivação (ou ativação) de linhas de telefonia confrontado com o número de vendas realizadas pelo call center. A necessidade das informações relacionadas a este fenômeno é percebida pelos três níveis hierárquicos:

(...) olha em relação a vendas é horrível (...) a gente faz uma venda $(\ldots)$ só que eles não falam por que não foi entregue (...) Quando chega ao final do mês a gente vai receber a nossa comissão, a gente não sabe (sic), se foi erro nosso, por 
que não foi entregue, se o cliente cancelou... (Entrevistado O2).

Ao questionar sobre melhorias no processo de determinação de exigências informacionais, não houve consenso entre os níveis hierárquicos. No entanto, alguns pontos já tratados em questões anteriores se repetiram. Sobre o tipo de informações técnicas em relação às quais gostariam de estar atualizados diariamente, as respostas apontaram para: indicadores de desempenho, conquista de metas, melhor divulgação de campanhas motivacionais e promoções internas, conversão de vendas, problemas de localização do operador no sistema e falta de informações sobre concorrência, dentre outros aspectos. O QUADRO 4 sintetiza as principais descobertas e os assuntos mais freqüentes referentes à categoria analítica 1 (determinação das exigências informacionais):

QUADRO 4- Síntese de questões mais freqüentes na categoria analítica 1

\begin{tabular}{|c|c|c|c|}
\hline & Estratégico & Tático & Operacional \\
\hline \multirow{8}{*}{ 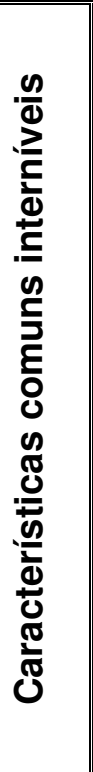 } & $\begin{array}{l}\text { informalidade na identificação } \\
\text { de necessidades } \\
\text { informacionais }\end{array}$ & $\begin{array}{l}\text { informalidade na identificação de } \\
\text { necessidades informacionais }\end{array}$ & $\begin{array}{l}\text { informalidade na identificação de } \\
\text { necessidades informacionais }\end{array}$ \\
\hline & $\begin{array}{l}\text { crença na certificação ISO } \\
\text { como uma condição } \\
\text { salvatoriana para questões de } \\
\text { toda espécie }\end{array}$ & $\begin{array}{l}\text { crença na certificação ISO como } \\
\text { uma condição salvatoriana para } \\
\text { questões de toda espécie }\end{array}$ & $\begin{array}{l}\text { crença na certificação ISO como } \\
\text { uma condição salvatoriana para } \\
\text { questões de toda espécie }\end{array}$ \\
\hline & $\begin{array}{l}\text { falta de informações de } \\
\text { conversão de vendas }\end{array}$ & $\begin{array}{l}\text { falta de informações de } \\
\text { conversão de vendas }\end{array}$ & $\begin{array}{l}\text { falta de informações de } \\
\text { conversão de vendas }\end{array}$ \\
\hline & $\begin{array}{l}\text { falta de informação sobre a } \\
\text { concorrência }\end{array}$ & $\begin{array}{l}\text { falta de informação sobre a } \\
\text { concorrência }\end{array}$ & $\begin{array}{l}\text { falta de informação sobre a } \\
\text { concorrência }\end{array}$ \\
\hline & $\begin{array}{l}\text { tratamento da questão } \\
\text { orçamentária entre } \\
\text { departamentos de forma } \\
\text { estratégica para o negócio }\end{array}$ & $\begin{array}{l}\text { tratamento da questão } \\
\text { orçamentária entre } \\
\text { departamentos de forma } \\
\text { estratégica para o negócio }\end{array}$ & \\
\hline & & $\begin{array}{l}\text { necessidade de informações } \\
\text { mais estratégicas do mailing }\end{array}$ & $\begin{array}{l}\text { necessidade de informações } \\
\text { mais detalhadas do mailing }\end{array}$ \\
\hline & $\begin{array}{l}\text { problemas com clareza das } \\
\text { informações }\end{array}$ & & $\begin{array}{l}\text { problemas com a clareza das } \\
\text { informações }\end{array}$ \\
\hline & & $\begin{array}{l}\text { Intranet ineficiente para atender } \\
\text { às necessidades informacionais }\end{array}$ & $\begin{array}{l}\text { Intranet ineficiente para atender } \\
\text { às necessidades informacionais }\end{array}$ \\
\hline & $\begin{array}{l}\text { falta de sintonia de informações } \\
\text { entre áreas para divulgação de } \\
\text { informações }\end{array}$ & $\begin{array}{l}\text { necessidade de indicadores de } \\
\text { performance e qualidade de } \\
\text { produção }\end{array}$ & $\begin{array}{l}\text { falta de informações sobre } \\
\text { processos seletivos e promoções } \\
\text { internas }\end{array}$ \\
\hline 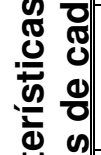 & $\begin{array}{l}\text { necessidade de formalização e } \\
\text { indicadores de desempenho } \\
\text { dos macro fluxos } \\
\text { organizacionais }\end{array}$ & & $\begin{array}{l}\text { escassez de atualizações de } \\
\text { promoções de venda }\end{array}$ \\
\hline 苋 & & & $\begin{array}{l}\text { falta de treinamento para atender } \\
\text { às necessidades informacionais }\end{array}$ \\
\hline Jु 응 & & & $\begin{array}{l}\text { mais agilidade na atualização de } \\
\text { estoque do sistema }\end{array}$ \\
\hline & & & $\begin{array}{l}\text { falta de informações sobre } \\
\text { campanhas motivacionais }\end{array}$ \\
\hline
\end{tabular}

Fonte: Dados da pesquisa.

Constatou-se que a maior parte dos problemas de exigências informacionais é comum entre dois ou três níveis da organização. Evidencia-se portanto, um claro problema de gaps de informação 
interníveis. Outra constatação refere-se à carência de informações do nível operacional, que indicou um grande número de necessidades, tanto na categoria de características comuns interníveis, quanto na de assuntos próprios do seu círculo de interesses. Isso aponta para o diagnóstico de que a grande maioria de colaboradores da empresa não tem suas exigências informacionais atendidas, uma vez que o corpo de colaboradores da AFTAC é composto por $95,83 \%$ de funcionários do nível operacional. Ressalta-se ainda - dentro do conceito da ecologia informacional - que a falta de informação externa sobre a concorrência impacta diretamente o negócio da empresa. Por fim, evidenciou-se que características próprias de cada círculo de interesse não apareceriam ou não interfeririam nas respostas dos entrevistados de outros níveis.

\subsection{Categoria de análise 2: processo de obtenção de informações}

Ao investigar a existência de algum tipo de formalidade de busca de informação, constatou-se que não houve consenso quanto às respostas. A maioria dos entrevistados afirma que não há processos formais:

(...) Acontece esporadicamente (processo de busca) ou quando estoura um problema, ou quando alguém sinaliza, ou às vezes o cliente contratante sinaliza (Entrevistado E3).

A pesquisa documental não identificou nenhum processo explícito e formal de busca de informações. Quanto aos meios de busca de informação, foram várias as ferramentas citadas pelos entrevistados. É necessário frisar que cada nível hierárquico indicou o ferramental e as fontes de busca condizentes com as necessidades informacionais vigentes daquele indivíduo ou setor, como tratado na categoria de análise anterior. Dessa forma, a natureza da busca por informações externas ou internas (CARVALHO; TAVARES, 2001; DAVENPORT, 1998) coaduna-se com as funções e responsabilidades de cada entrevistado. Adiciona-se a esta análise o fato de que a organização investe em um projeto de governança em TI que, dentre outros objetivos, visa centralizar as fontes de informação.

Quando questionados sobre os principais obstáculos experimentados na busca por informações e suas causas, não houve consenso entre as respostas. Alguns colaboradores afirmam não terem dificuldade para buscar informações, enquanto outros apontam oportunidades de melhorias. Alguns fatores, entretanto, mostraram-se comuns, como demonstram os exemplos dos depoimentos contidos no QUADRO 5. 
QUADRO 5- Principais dificuldades encontradas na busca de informações

\begin{tabular}{|c|c|c|c|}
\hline & Estratégico & Tático & Operacional \\
\hline 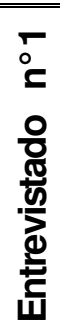 & $\begin{array}{l}\text {-Línguas diferentes, } \\
\text { tempo, adequação de } \\
\text { linguagem a públicos } \\
\text { específicos (níveis } \\
\text { hierárquicos) }\end{array}$ & $\begin{array}{l}\text {-Sem dificuldades } \\
\text {-Ineficiência da intranet para } \\
\text { a busca de algumas } \\
\text { informações }\end{array}$ & $\begin{array}{l}\text {-Timidez de operadores para } \\
\text { pedir informações }\end{array}$ \\
\hline 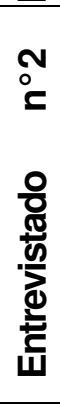 & $\begin{array}{l}\text {-Layout físico da } \\
\text { empresa } \\
\text {-Línguas e culturas } \\
\text { diferentes }\end{array}$ & $\begin{array}{l}\text {-Intranet confusa para } \\
\text { operadores } \\
\text {-Falta de treinamento para os } \\
\text { supervisores extraírem } \\
\text { informações desejadas da } \\
\text { intranet } \\
\text {-Ineficiência da intranet para } \\
\text { a busca de algumas } \\
\text { informações }\end{array}$ & $\begin{array}{l}\text {-Ineficiência da intranet para } \\
\text { a busca de algumas } \\
\text { informações }\end{array}$ \\
\hline 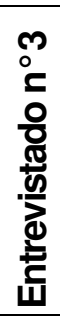 & $\begin{array}{l}\text {-Falta de padronização } \\
\text { e automação de } \\
\text { relatórios }\end{array}$ & $\begin{array}{l}\text {-Resistência a novas } \\
\text { tecnologias }\end{array}$ & $\begin{array}{l}\text {-Faltam informações sobre a } \\
\text { concorrência } \\
\text {-Demora na atualização de } \\
\text { estoques } \\
\text {-Ineficiência da intranet para } \\
\text { a busca de algumas } \\
\text { informações }\end{array}$ \\
\hline
\end{tabular}

Fonte: Dados da pesquisa.

Constatou-se que a ineficiência da intranet para a busca de informação é um problema para os níveis que atuam diretamente com essa ferramenta. Esse fato acarreta conseqüências diretas à produtividade da operação. A maior contradição está no fato de que a intranet é considerada, pelos níveis operacional e tático, como a principal fonte de informação técnica e, antagonicamente, é apontada como o mais falho dos processos de obtenção de informação. Buscou-se levantar a opinião dos entrevistados sobre a possibilidade de se centralizar toda a documentação técnica em um único local de acesso. A maioria acredita nos benefícios, mas acha que ainda há muito a ser feito, além das dificuldades técnicas para a concretização da idéia. Houve convergência de respostas tanto no quesito intra quanto interníveis da empresa, como ilustra o depoimento abaixo:

(...) Coloquei um desafio pesado na minha galera (sic) de engenharia de processos e de $\mathrm{TI}$, da forma que tenha um único database na empresa (...) acho fundamental (Entrevistado E1). 
Contraditoriamente, quando analisado o procedimento da certificação ISSO, que trata da "Divulgação e atualização de informações na intranet", a prática mostra-se novamente diferente do discurso (ANDRADE, 2008):

(...) Acompanhar todo o processo de inclusão/exclusão do material na Intranet do Operador de Telemarketing até que o mesmo (sic) seja publicado, respeitando a "prioridade" indicada:

\begin{tabular}{cc}
\hline Classificação de Prioridades \\
\hline 1 & 10 \\
Minutos \\
\hline 2 & 01 Hora \\
\hline 3 & 2 Horas \\
\hline 4 & 24 Horas
\end{tabular}

Buscou-se, através de uma questão complementar, identificar se os usuários da informação encontram as informações consistentes, estruturadas, completas e confiáveis em suas atividades (DAVENPORT, 1998; BEAL, 2004; McGEE; PRUSAK, 1994). Não se pode dizer que houve consenso entre as respostas, sendo, portanto, inconclusiva esta questão.

Apesar do testemunho acima, o discurso colhido em uma entrevista, em revista especializada, mostra novamente uma situação diferente do que foi aferido na presente pesquisa:

(...) sem um programa de comunicação que funcione, é difícil alinhar as pessoas com a missão da empresa e se torna quase impossível qualquer ação de comunicação eficaz. A AFTAC focou sua estratégia de comunicação no público interno (...) (ANDRADE, 2008).

\subsection{Categoria de análise 3: processo de distribuição de informações}

Ao apurar e existência de incentivos formais de distribuição e compartilhamento de informações, a pesquisa documental apontou para documentos de normalização da ISO. Foi possível averiguar que há formalização do processo de distribuição, mesmo que em entrevista os usuários afirmem não conhecer tais processos:

(...) estar buscando mais trabalhar juntos (sic) e não separados na mesma informação, em termos de incentivo existe, na prática acontece pouco (Entrevistado 3).

(...) a AFTAC assegura que seus processos são executados sob condições controladas, ou seja: a) Disponibilidade de informações que descrevem os serviços; b) Existência de 
procedimentos documentados definindo métodos de trabalho, onde necessário (ANDRADE, 2008).

Essa citação se choca com um dos valores organizacionais divulgados pela empresa, e que, portanto, contradiz a prática vigente na organização pesquisada:

(...) valores da empresa: Integração - Compartilhar conceitos, metas, conhecimentos e experiências entre todos os colaboradores, visando o crescimento profissional em prol de objetivos comuns (ANDRADE, 2008).

Constatou-se que as dificuldades de disseminação de informação são diversas, algumas já citadas nas categorias de análise anteriores. Apesar da variedade de fatores levantados, o problema da falta de ações de feedback (recebimento e assimilação da informação divulgada) mostrou-se constante entre os entrevistados. Além disso, a comunicação horizontal é falha nos níveis estratégico e tático, apresentando certa carência de difusão de informações intra-nível no staff da empresa. Na base da pirâmide, o problema é a comunicação vertical, que sofre com o repasse de informações entre líderes e subordinados.

No nível estratégico, foram apontadas ainda dificuldades quanto à difusão de informações incorretas ou não padronizadas, o mau uso da ferramenta de e-mail, a falta de organização e o senso de prioridade, e ainda a ausência de reuniões de nivelamento do staff. No nível tático, evidenciou-se a falta de tempo para absorver todas as informações, dificuldades no uso da intranet e a falta de reuniões para troca de informações e experiências entre equipes.

Averiguou-se, no nível operacional, que os problemas estão relacionados à comunicação entre supervisores e operadores. Segundo relatos de operadores, a grande queixa está no não repasse de informações por parte dos supervisores, que seriam seus líderes imediatos e o maior canal humano de comunicação:

(...) acabo sabendo, mas tem que procurar, (...) alguns (supervisores) passam para os operadores e outros não (...) pelo menos com uns que eu trabalho (sic) nem todos dão essas informações (Entrevistado 04).

A pesquisa buscou também levantar quais espaços físicos e virtuais existem na empresa para troca de informações (DAVENPORT, 1998), ainda que estes não sejam utilizados de maneira formal. Foram identificados vários espaços físicos, através de entrevistas e observação direta, mas, em relação aos espaços virtuais, a intranet ainda não apresenta a estrutura necessária para trocas, uma vez que se trata de uma intranet operacional. Sua arquitetura e o fluxo de informações são unidirecionais, ou seja, operadores não conseguem contribuir com informações, apenas as recebem, inviabilizando o processo de troca. Some-se a isto o fato de que os demais setores de staff da empresa não 
operam com o mesmo sistema. Ao verificar a intencionalidade da empresa em investir na tecnologia para difusão de informações, verificou-se que há esforços claros de avanços neste quesito. Houve unanimidade dos entrevistados, como demonstra o depoimento abaixo:

(...) Eu percebo um foco bem grande nisso. (...) acredito muito que a médio, longo prazo nós também estejamos fornecendo recursos pro mercado no que diz respeito à tecnologia (Entrevistado T1).

\subsection{Categoria de análise 4: processo de uso de informações}

Iniciando a análise, foram verificadas quais as ações formais de ampliação e melhoria do uso da informação. Constatou-se que há pouca formalidade no processo e que existem ilhas de melhorias relacionadas à utilização da informação, como o projeto de governança em TI e os relatórios de desempenho e qualidade disponibilizados para o uso.

Convergentemente à questão anterior, buscou-se identificar políticas de incentivo ao uso da informação. As respostas apontam para estímulos constantes, sem, no entanto, haver processos formais para tal. Ao levantar as principais dificuldades experimentadas pelos entrevistados no uso das informações, foi possível identificar perfis diferentes de complicadores entre os níveis estratégico/tático e o nível operacional. Verificou-se que o excesso de informação e a velocidade dos acontecimentos são os principais obstáculos ao processamento e ao uso da informação nos níveis estratégico e tático:

(...) tem muito trabalho de produção da informação e pouquíssimo trabalho de interpretação da informação (Entrevistado E1).

No nível operacional, ficou clara a necessidade de agilidade na atualização das informações e de clareza nas mesmas, fator complicador no quesito uso:

(...) As informações deviam ser mais claras, às vezes é bem, bem diferente. Acho que falta clareza mesmo (Entrevistado O3).

Exploradas as dificuldades, partiu-se para o levantamento de ações de controle que, de alguma forma, buscassem mensurar o quanto se usa as informações na organização, como por exemplo, estimativas do número de acessos a determinados bancos de dados ou sistemas. A maioria dos entrevistados não conseguiu contribuir com a questão ou apontou uma situação negativa sobre a existência de controle. A pesquisa documental, da mesma forma, não conseguiu substratos que pudessem acrescentar à análise da questão. 
A pesquisa explorou também a prática da organização no registro de experiências de aprendizagem (CHOO, 2003) através do uso da informação. Constatou-se que a maioria dos processos de absorção de conhecimento acontece de maneira informal, sendo, portanto, pouco comum o registro de experiências e melhorias. No entanto, foram encontrados na pesquisa documental indícios voltados para a preocupação de registros de experiências de aprendizagem, o que evidencia a distância entre prática e discurso:

(...) incentiva de uma maneira tão informal quanto o próprio acontecimento, então isso ainda precisa estruturar muito"(Entrevistado T1).

Recursos Humanos / São definidos os critérios para: manter registros apropriados de educação, treinamento, habilidade e experiência (ANDRADE, 2008).

Por fim, a pesquisa contemplou a demanda por retroalimentação dentro do conceito de sistemas informacionais (LAUDON; LAUDON, 1999). 0 feedback, ou a retroalimentação, atua como uma saída usada para fazer ajustes e refinamentos nos processos e sistemas de informação vigentes. A retroalimentação fecha o sistema, agindo como uma variável que permite sinergia ao conjunto de componentes inter-relacionados que coleta (ou recupera), processa, armazena e distribui informação para dar suporte à tomada de decisão. Nesse sentido, buscaram-se evidências que pudessem comprovar a existência de tais iniciativas. A pesquisa identificou fragmentos de retroalimentação em projetos internos. No entanto, constatou-se que o processo de feedback é percebido apenas no nível estratégico, nos demais níveis não houve identificações relevantes desses processos. Outros documentos comprovam a preocupação com a retroalimentação, como os formulários de avaliação de reação e de eficácia, uma vez mais apenas percebidos no nível estratégico.

\section{Conclusões}

O presente estudo se propôs a investigar e analisar as práticas e os processos vigentes de gestão estratégica da informação (GEI) em uma empresa de call center. Utilizou-se para isso o modelo de Davenport (1998), que trata de processos de gerenciamento de informações.

A primeira categoria de análise avaliada tratou da identificação de necessidades informacionais. Na avaliação dos entrevistados sobre o nível 
de informação efetivamente disponibilizada e recebida, concluiu-se que há gaps ou hiatos entre o que de fato se tem disponível e o que é necessário para o exercício das atividades de cada entrevistado. Conclui-se, portanto, que o processo de identificação de necessidades informacionais é desestruturado e informal. Muitas são as exigências informacionais não atendidas, em função principalmente da falta de identificação das mesmas. Gaps de informação estão presentes intra e interníveis, evidenciando necessidades comuns a muitas atividades do call center. Apesar de identificados os fragmentos do processo, não se pode afirmar que haja uma estruturação concisa e eficiente desta etapa do processo de GEI.

Em relação ao processo de busca de informação, as descobertas apontaram para um processo desconexo, sem um fluxo concatenado de ações e procedimentos. Inexistem processos significativos e formais de busca de informações. Tímidos fragmentos aparecem, mas são desconjuntados do todo, impedindo assim uma estruturação que caracterize processos planejados de gestão estratégica da informação. 0 processo é desestruturado, ad hoc e não foi verificada uma integração entre os processos normativos e a prática vigente, evidenciando-se uma distância entre discurso e prática. Os vários meios de busca levantados mostraram-se incapazes de encadear métodos eficientes de busca. Não há um repositório central de informações, apesar da identificação de benefícios na centralização da documentação técnica. Constatou-se também que os cuidados referentes à classificação de informações (quando captadas para arquivamento), à padronização de informações, ao uso de taxonomias e aos critérios de registro de documentos, estão mais presentes na documentação da ISO do que na prática efetiva desses itens. Conclui-se, portanto, haver uma dissonância entre discurso e prática na organização estudada.

Sugere-se o estudo da viabilidade de implementação de sistemas de recuperação de informação e Gestão Eletrônica de Documentos (GED). Constatou-se que a intranet é a ferramenta mais requisitada para a busca de informações no nível tático e operacional, e também a que mais apresenta necessidades de melhorias. Comprovou-se sua ineficiência a partir da dificuldade de acesso a dados, da falta de lógica da disposição de informações, da morosidade de atualização dos dados, e da estruturação pouco amigável e intuitiva. Acredita-se que as mudanças nesses fatores teriam impacto em outro item avaliado, a comunicação da empresa. Se a intranet fosse redesenhada, haveria grandes possibilidades de implementar uma comunicação mais ágil e eficiente, abandonando o modelo unidirecional ainda em uso.

No que diz respeito ao processo de distribuição da informação, conclui-se que o processo é desestruturado. A análise de dados evidencia alguns esforços da organização no sentido de melhor distribuir suas informações, além de grande disponibilidade de investimento em tecnologia, na crença de que este seria um caminho a ser seguido. Contudo, os esforços não são alinhados e não há fluxos sustentáveis, formais, interligados e estruturados, de forma a caracterizar um processo 
consistente de disseminação de informações. Os incentivos à distribuição da informação se dão de maneira informal e acontecem principalmente através de reuniões. Processos formalizados foram identificados em documentos da ISO, embora os entrevistados desconheçam tais preceitos, - que denota novamente um descompasso entre discurso e prática organizacional.

Complementarmente, sugere-se ainda um espaço para a troca de informações mais eficiente que a atual intranet e mais estruturado que as trocas de e-mails. Redes de conhecimento ou comunidades de práticas poderiam ser criadas, de forma a patrocinar o compartilhamento de informações e conhecimentos. Tal como na segunda etapa do processo de GEI, a intranet mostrou-se a maior responsável pela distribuição de informação e, concomitantemente, a menos qualificada para fazê-lo. Seu fluxo de informação unilateral e sua incapacidade para envolver demais setores fazem dessa ferramenta um entrave para a difusão de informações na organização estudada.

Quanto ao processo de uso da informação, as evidências apontaram novamente para ilhas de uso informacional. Dentre as quatro etapas, no entanto, esta foi a que a empresa, curiosamente, apresentou melhores resultados. A pesquisa revelou que a AFTAC apresenta interessantes iniciativas de uso da informação, com bons potenciais para o desenvolvimento de sistemas de retroalimentação. Entretanto, não há consistência de ações interligadas e direcionadas para o uso ostensivo da informação. Apesar de apresentar fragmentos do processo, a integração de esforços intra e interníveis não é atingida. Averiguou-se que o uso da informação faz-se presente principalmente em relatórios de performance, além de indicadores de desempenho, qualidade e produtividade gerados pela empresa. Concomitantemente, constatou-se que não há políticas formais de incentivo ao uso da informação, bem como não há ações de controle do uso da informação ou práticas de registros formais de experiências de colaboradores. As dificuldades levantadas apontaram para a falta de clareza e a demora na atualização das informações. Constatouse ainda a incapacidade de se gerenciar informações geradas pelo excesso de produção informacional nos níveis tático e estratégico, em função da grande elaboração de indicadores de produtividade, como identificado na categoria analítica 1 . Inexistem políticas usuais de incentivo ao uso da informação, a não ser aquelas documentadas pela ISO e que, em grande parte, são desconhecidas pelos entrevistados, evidenciando um descompasso entre discurso e prática. Conclui-se que tal como nas categorias de análise anteriores, o processo é desconexo e sem estruturação. Mais uma vez, não foram identificados esforços para um processo convergente de gerenciamento da informação que abrangesse interesses comuns da empresa.

Avaliadas as quatro etapas do processo de gerenciamento de informações da AFTAC Call Center, e respondendo à pergunta de pesquisa deste estudo, confirma-se a inexistência de uma estrutura minimamente representativa, que possa ser caracterizada dentro dos moldes da literatura como processo legítimo de gestão estratégica da informação. 
Conclui-se que, apesar dos fragmentos encontrados, não há consistências que justifiquem a classificação como sendo a de um processo formal e estruturado. As ilhas informacionais encontradas não conversam entre si, não apresentam sinergia de esforços e tão pouco encadeamento de objetivos comuns da organização. O processo existente é desconexo e os esforços, apesar de válidos, são insuficientes para o atendimento às necessidades da organização. A estrutura informacional existente é frágil, ad hoc e não foi verificada integração entre as iniciativas normalizadas da ISO e a prática vigente, evidenciando-se uma distância entre discurso e prática.

Contudo, há de se destacar que a organização pesquisada é um start up e, como tal, é compreensível que ainda não tenha estruturado seu processo informacional diante de tão pouco tempo de operação. Mediante o rápido processo evolutivo da empresa no Brasil e a origem advinda de um grupo que tem como expertise competências relacionadas à tecnologia da informação, espera-se que o diagnóstico evolua e evoque mudanças significativas.

No que se refere às limitações da pesquisa, apontam-se os seguinte fatores: (i) ser um caso único, o que não reflete necessariamente a realidade de um setor como um todo; (ii) ser um estudo qualitativodescritivo de um único caso, sem a possibilidade de generalização para um universo estatisticamente válido; (iii) ser uma pesquisa qualitativa cujo objetivo era levantar e descrever variáveis. As variáveis não são generalizáveis, mas podem ser reunidas em um escala que, se validada, poderá ser aplicada em um estudo quantitativo com vistas à generalização dos resultados.

\section{Referências}

ALVARENGA NETO, R. C. D.; BARBOSA, R._R.; CENDÓN, B. V. A construção de metodologias de pesquisa qualitativa com vistas à apreensão da realidade organizacional brasileira: estudos de casos múltiplos para proposição de modelagem conceitual integrativa. Inf. \& Soc.: Est, João Pessoa, v. 16, n._2, p._69-86, jul/dez. 2006.

ANDRADE. E. A. Gestão da informação em uma empresa de call center: investigação e análise sociotécnica dos processos e práticas vigentes. 2008. 162 f. Dissertação (Mestrado Profissionalizante em Administração) FEAD, Belo Horizonte, 2008.

BARBOSA, A. C. Q., FERRAZ,_D. M., ÁVILA, F. B. Recursos humanos em direção ao futuro?: a gestão de competências em empresas de telefonia móvel. In: ENCONTRO DA ASSOCIAÇÃO NACIONAL DE PÓS-GRADUAÇÃO E PESQUISA EM ADMINISTRAÇÃO (EnANPAD), 28., Curitiba, 2004. Anais... São Paulo: ANPAD, 2004.

BEAL, A. Gestão Estratégica da Informação: como transformar a informação em fatores de crescimento e de alto desempenho nas organizações. São Paulo: Atlas, 2004. 
BERGERON, P. Information resources management. ARIST, v._31, p._263300, 1996.

CALDAS, M. P.; AZEVEDO, M. C. O discurso evolucionista e a prática involutiva: um estudo empírico exploratório sobre o impacto de mudanças tecnológicas sobre o desenho do trabalho em Call centers. In: ENCONTRO DA ASSOCIAÇÃO NACIONAL DE PÓS-GRADUAÇÃO E PESQUISA EM ADMINISTRAÇÃO (EnANPAD), 27., Atibaia,_2003. Anais... São Paulo: ANPAD, 2003.

CARVALHO, G._M._R.; TAVARES, M. S. Informação e conhecimento, uma abordagem organizacional. Rio de Janeiro: Qualitymark, 2001.

CASSIOLATO, J. E.; LASTRES, H. M. M. Globalização e inovação localizada: experiências de sistemas locais no Mercosul. Brasília: IBICT/IEL, 1999

CHOO, C. W. A Organização do conhecimento: como as organizações usam a informação para criar significado, construir conhecimento e tomar decisões. São Paulo: Senac, 2003.

DAVENPORT, T._H. Ecologia da informação: por que só a tecnologia não basta para o sucesso na era da informação._São Paulo: Futura, 1998.

LASTRES, H._M._M; FERRAZ J._C. Economia da informação, do conhecimento e do aprendizado. In: LASTRES, H. M. M.; ALBAGLI, S. (Orgs.). Informação e globalização na era do conhecimento. Rio de Janeiro: Campus, 1999.

LAUDON, C.: LAUDON, P. Gerenciamento de Sistemas de Informação. Rio de Janeiro: LTC, 1999.

LAZARTE, L. Ecologia cognitiva na sociedade da informação. Ci. Inf., Brasília, v. 29, n. 2, p. 43-51, maio/ago. 2000. Disponível em: <http://www.scielo.br/pdf/ci/v29n2/a06v29n2.pdf >. Acesso em: 4 out. 2007.

LYMAN, P.; VARIAN, H. R. How much information. 2003. Disponível em: $\leq$ http://www2.sims.berkeley.edu/research/projects/how-much-info-

2003/execsum.htm>. Acesso em: 18_set. 2007.

MADRUGA, R. Gestão moderna de call center e telemarketing. São Paulo: Atlas 2006

MALHOTRA, K. et al._Introdução à pesquisa de marketing. São Paulo: Prentice Hall, 2005.

McGEE, J.; PRUSAK, L. Gerenciamento Estratégico da Informação: aumente a competitividade e a eficiência de sua empresa utilizando a informação como ferramenta estratégica. Rio de Janeiro: Campus, 1994.

McHATTON, R. J. Telemarketing total. São Paulo: McGraw-Hill, 1990

MILES, M. B.; HUBERMAN, A. M. Qualitative data analysis: a sourcebook of new methods. Newbury Park, California: Sage Publications,1984. 
TRIVIÑOS, A._N._S. Introdução à pesquisa em ciências sociais: a pesquisa qualitativa em educação. São Paulo: Atlas, 1987.

VILLELA, D. R. et al. Aprendizagem organizacional em Call centers: uma análise sobre as dicotomias entre o discurso e a prática e seus efeitos. In: ENCONTRO DA ASSOCIAÇÃO NACIONAL DE PÓS-GRADUAÇÃO E PESQUISA EM ADMINISTRAÇÃO (EnANPAD), 29., Brasília, 2005. Anais... São Paulo: ANPAD, 2005.

VON KROGH, G; ICHIJO, K.; NONAKA, I. Facilitando a criação do conhecimento. Rio de Janeiro: Campus, 2001.

YIN $_{\llcorner}$R. K. Estudo de caso: planejamento e métodos. Porto Alegre: Bookman, 2005. 